\title{
The Effects of the relA Gene on the Synthesis of Aminoacyl-tRNA Synthetases and Other Transcription and Translation Proteins in Escherichia coli B
}

\author{
Robert M. Blumenthal*, Peggy G. Lemaux*, Frederick C. Neidhardt, and Patrick P. Dennis ${ }^{1}$ \\ Department of Microbiology, University of Michigan, Ann Arbor, Michigan 48109, U.S.A. \\ ${ }^{1}$ Department of Microbiology, University of British Columbia, Vancouver, British Columbia V6T 1W5 Canada
}

Summary. The effects of a partial restriction of valyltRNA aminoacylation on the synthesis of aminoacyltRNA synthetases, ribosomal proteins, and other translation and transcription proteins were examined in otherwise isogenic stringent $\left(\mathrm{rel}^{+}\right)$and relaxed (relA 1 ) derivatives of E.coli $\mathrm{B}$. The synthesis of individual ribosomal proteins, elongation factor $G$, and to a lesser extent elongation factors $\mathrm{Tu}$ and $\mathrm{Ts}$, and the valyl- and arginyl-tRNA synthetases was found to be subject to the influence of the stringent control system. The synthesis of the $\alpha$ and $\beta$ subunits of RNA polymerase and several of the aminoacyl-tRNA synthetases, in contrast, is either not subject to the influence of the stringent control system, or is subject to additional regulatory constraints.

\section{Introduction}

A large body of evidence suggests that the components of the translation machinery of Escherichia coli are coordinately regulated. Specifically, there is evidence for coordinate regulation during steady-state growth of all ribosomal proteins ( $r$-proteins) (Dennis, 1974; not measured: S1, L31, and L34), the three species (5S, 16S and 23S) of ribosomal RNA (Galibert et a1., 1967), and elongation factor G (EF-G) (Gordon, 1970; Reeh, personal communication). In addition, tRNA (Skjold et al., 1973; Dennis, 1972), elongation factor $\mathrm{Tu}$ (EF-Tu) (Neidhardt et al., 1976), and several (if not all) of the aminoacyl-tRNA synthetases (Neidhardt et al., 1976) are regulated in parallel with ribosomes during steady-state growth.

Another characteristic of the regulation of the translational machinery involves the "stringent response," which includes severe reductions in the rates of accumulation of ribosomal RNA (Nikolaev et al., $1973 \mathrm{a}$ and b), ribosomal proteins (Dennis and Nomura, 1974), and EF-G (Furano and Wittel, 1976),

* This work is in partial fulfillment of the requirements of the University of Michigan for the Ph.D. degrees of R.M.B. and P.G.L. brought about by the relA gene-dependent production of guanosine tetraphosphate (ppGpp) following a reduction in the charging level of one (or more) of the tRNA species (Stent and Brenner, 1961; Fiil et al., 1973). In this paper we have attempted to determine the influence of the stringent control system on the synthesis of other proteins involved at various stages of the transcription and translation processes.

\section{Materials and Methods}

Bacterial Strains. Three isogenic derivatives of E. coli B AS19 were used: NF314 (leu- val ${ }^{+}$rel $\left.^{+}\right)$, NF536 (leu ${ }^{-}$val $S^{\text {ts }}$ rel $\left.^{+}\right)$, and NF537 (leu ${ }^{-}$val ${ }^{\text {ts }}$ relA1). The temperature-sensitive lesion in the valyl-tRNA synthetase $\left(\right.$ val $\left.S^{\mathrm{s}}\right)$ has been described (Fiil et al., 1973). The synthesis of ppGpp, rRNA, $r$-proteins and $r$-protein mRNA in these strains has also been described at various semipermissive and restrictive temperatures (Fiil et al., 1973; Dennis and Nomura, 1974, 1975).

Growth and Labeling of Cells. The growth of these cultures was performed as described (Dennis and Nomura, 1974), in glucose minimal medium. The labeling protocol is summarized in Figure 1. Exponential phase cultures grown at $29.5^{\circ}$ (permissive temperature) were labeled with a small amount of $\left[{ }^{14} \mathrm{C}\right]-\mathrm{L}$-isoleucine $(330 \mathrm{mCi} /$ $\mathrm{mmol} ; 3 \mathrm{nmol} / \mathrm{ml}$ of culture) at an $\mathrm{A}_{460}$ of $0.05-0.10$. This amount of radioactivity was rapidly taken up from the growth medium and randomly distributed into cellular protein. When the $A_{460}$ reached 0.3 , the appropriate cultures were shifted to $35.5^{\circ}$ (semipermissive temperature). After incubation of the cultures at the new temperature for $15 \mathrm{~min},\left[{ }^{3} \mathrm{H}\right]-\mathrm{L}$-isoleucine $(26 \mathrm{Ci} / \mathrm{mmol}$;

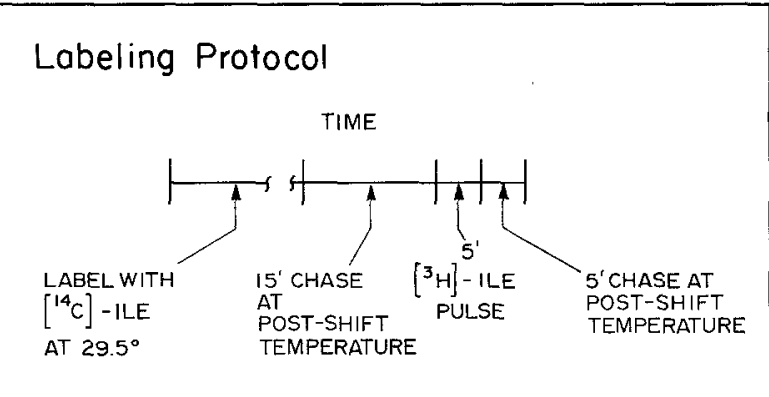

Fig. 1. See Materials and Methods for details 
$750 \mathrm{pmol} / \mathrm{ml}$ of culture was added. This radioactivity was randomly distributed into proteins synthesized at $35.5^{\circ}$. Incorporation was terminated through the addition of $50 \mu \mathrm{g} / \mathrm{ml}$ each of unlabeled L-isoleucine, L-leucine, and L-valine. After $5 \mathrm{~min}$, cultures were stopped by pouring them over crushed ice with $10^{-2} \mathrm{M}$ sodium azide. The cultures were submitted to low-speed centrifugation and the pellets were stored frozen at $-80^{\circ}$.

O'Farrell Electropherograms. To submit samples of the labeled cultures to resolution on the two-dimensional electropherograms (O'Farrell, 1975), the culture samples were treated as described previously (Blumenthal et al., 1976). Proteins were identified on these electropherograms as described (Blumenthal et al., 1976); the locations of the proteins studied here have been reported previously (O'Farrell, 1975; Furano and Wittel, 1976; Reeh et al., 1976a; Blumenthal et al., 1976; Neidhardt et al., 1976). Protein spots were cut from dried gels with a 15 gauge (or smaller) hypodermic needle. Cuts were then oxidized in a Packard Sample Oxidizer (Packard Instruments), counted in a refrigerated liquid scintillation counter, and corrected with an external standard. The isotope ratios of the extracts were determined both by precipitating a sample of the extract in $5 \%(\mathrm{~W}: \mathrm{V})$ trichloracetic acid, filtering the precipitate onto filter paper, and counting the filter as described above, and by oxidizing a sample of the extract directly and counting as described.

Other Procedures. Ribosomal proteins were extracted from samples of these labeled cultures as described (Dennis and Nomura, 1974) and were resolved through the electrophoresis procedure of Kaltschmidt and Wittmann (1970). Individual ribosomal proteins were then processed and counted as described above.

Elongation factor $G$ was measured through antibody precipitation from unfractionated extracts, followed by electrophoresis on $7.5 \%$ SDS acrylamide gels as described by Roberts and Roberts (1975). The antibody preparation was the kind gift of $\mathrm{H}$. Weissbach to M. Nomura.

\section{Results}

Four exponential cultures at $29.5^{\circ}$ (one each of NF536 and NF537, and two of NF314) were first labeled with $\left[{ }^{14} \mathrm{C}\right]$-isoleucine, then shifted to either $29.5^{\circ}$ or $35.5^{\circ}$ and labeled with $\left[{ }^{3} \mathrm{H}\right]$-isoleucine as shown in Figure 1. The $\left[{ }^{3} \mathrm{H} /{ }^{14} \mathrm{C}\right]$ ratio for a given protein, when divided by the isotope ratio of the total extract, is a measure of the differential rate of synthesis of that protein after $15 \mathrm{~min}$ at $35.5^{\circ}$ (relative to the synthesis rate at $29.5^{\circ}$ ) and has been used to gauge the effect of relA gene function. These measurements are normalized and thus are independent of the recoveries of the proteins in the gels.

The values presented are generally the average result from several determinations. It was assumed that there was no significant turnover of the completed proteins labeled with $\left[{ }^{3} \mathrm{H}\right]$-isoleucine during the short chase period. Essentially identical results were obtained in an experiment where the post-pulse chase time was increased from 5 to $30 \mathrm{~min}$ and the chase temperature reduced to $29.5^{\circ}$ (unpublished results). It was further assumed that $15 \mathrm{~min}$ of incubation at the semi-permissive temperature is sufficient for the adjustment of the cells to the partial restriction of valyl-tRNA aminoacylation. These conditions are clearly sufficient to elicit the stringent or relaxed responses but have a minimal effect on the rate of accumulation of total cellular protein (Dennis and Nomura, 1974). Presumably they also minimize any secondary and nonspecific effects on the synthesis and stability of the individual proteins which might result from a more severe restriction on protein synthesis and a greater imbalance in the growth of the culture.

Ribosomal Proteins. S1, L7, and L12 from the O'Farrell gels, were examined to establish a baseline against which the response of the transcription proteins, translation proteins and aminoacyl-tRNA synthetases could be compared. The results are shown in Table 1. The average values for the relative differential rates of synthesis of 9 individual ribosomal proteins separated on Kaltschmidt-Wittmann gels are also shown. The individual $r$-proteins isolated using either of the two separation systems gave essentially identical results (Table 1) and are consistent with previous measurements (Dennis and Nomura, 1974).

Elongation Factors. EF-G, EF-Tu, and EF-Ts were studied, and the results are shown in Table 1. Protein EF-G responded in a manner nearly identical to the ribosomal proteins. Protein EF-Tu responded to the restrictions qualitatively like the ribosomal proteins, but to a much lesser degree in the $\mathrm{relA}^{+}$restricted culture. EF-Tu also showed a significant response to the temperature-shift in the val $S^{+}$(unrestricted) culture, unlike EF-Ts, which did not. The responses of EF-Ts in the restricted cultures were intermediate to those of EF-Tu and EF-G.

Transcription Proteins. The $\alpha$ and $\beta$ subunits of RNA polymerase, and termination factor $\rho$, were examined because of the intimate relationship that exists between transcription and translation. The results are shown in Table 1. Each transcription protein responded in a distinct manner, and none appear to be "stringently" regulated (see Discussion). Similar results have been obtained from experiments in which RNA polymerase subunits were obtained following either affinity chromatography on DNA-Sephadex, or specific antibody precipitation and subsequent electrophoresis on SDS acrylamide gels (Dennis and Burgess, unpublished results).

Aminoacyl-tRNA Synthetases. The aminoacyl-tRNA synthetases specific for arginine (ArgRS), glutamate (GluRS), glutamine (GlnRS), glycine (GlyRS), isoleucine (IleRS), leucine (LeuRS), lysine (LysRS), phenylalanine (PheRS), and valine (ValRS) were examined because of their role in the translation process. Our 
Table 1. Relative differential rates of synthesis of various proteins

\begin{tabular}{|c|c|c|c|c|}
\hline Protein & $\frac{1}{N F 31430^{\circ}}$ & $\begin{array}{l}2 \\
\text { NF314 } 30^{\circ} \rightarrow 35^{\circ}\end{array}$ & $\begin{array}{l}3 \\
\text { NF536 }\end{array}$ & $\begin{array}{l}4 \\
\text { NF537 }\end{array}$ \\
\hline [Total extract & 1.21 & 1.85 & 1.68 & $1.68]$ \\
\hline \multicolumn{5}{|c|}{ Ribosomal proteins } \\
\hline $\mathrm{L} 7$ & $1.09 \pm 0.09^{b}$ & $1.11 \pm 0.09^{\mathrm{b}}$ & $0.78 \pm 0.02^{\mathrm{b}}$ & $1.33 \pm 0.09^{\mathrm{b}}$ \\
\hline $\mathrm{L} 12$ & $1.08 \pm 0.12^{b}$ & $1.03 \pm 0.11^{\mathrm{b}}$ & $0.46 \pm 0.07^{b}$ & $1.59 \pm 0.17^{\mathrm{b}}$ \\
\hline $\mathrm{S} 1$ & $1.10 \pm 0.16^{\mathrm{a}}$ & $1.06 \pm 0.15^{\mathrm{a}}$ & $0.72 \pm 0.09^{\mathrm{a}}$ & $1.45 \pm 0.15^{\mathrm{a}}$ \\
\hline Ave & 1.09 & 1.07 & 0.65 & 1.46 \\
\hline $\mathrm{r}-\mathrm{P} \mathrm{Ave}^{\mathrm{c}}$ & 0.96 & 0.89 & 0.62 & 1.68 \\
\hline \multicolumn{5}{|c|}{ Elongation factors } \\
\hline EF-Tu & $1.06 \pm 0.08^{b}$ & $1.24 \pm 0.12^{\mathrm{b}}$ & $0.92 \pm 0.08^{\mathrm{b}}$ & $1.35 \pm 0.09^{\mathrm{b}}$ \\
\hline $\mathrm{EF}-\mathrm{Ts}$ & $1.05 \pm 0.10^{\mathrm{a}}$ & $1.10 \pm 0.13^{\mathrm{a}}$ & $0.82 \pm 0.04^{\mathrm{a}}$ & $1.49 \pm 0.25^{\mathrm{a}}$ \\
\hline $\mathrm{EF}-\mathrm{G}$ & $1.07 \pm 0.09^{\mathrm{b}}$ & $0.98 \pm 0.09^{\mathrm{a}}$ & $0.65 \pm 0.03^{\mathrm{b}}$ & $1.47 \pm 0.13^{\mathrm{b}}$ \\
\hline$E F-G^{d}$ & 0.94 & 0.94 & 0.62 & 1.43 \\
\hline \multicolumn{5}{|c|}{ Transcriptional proteins } \\
\hline$\alpha$ RNAP & $1.05 \pm 0.05^{\mathrm{b}}$ & $1.08 \pm 0.06^{b}$ & $1.01 \pm 0.07^{\mathrm{b}}$ & $1.14 \pm 0.10^{\mathrm{b}}$ \\
\hline$\beta$ RNAP & $1.08 \pm 0.09^{b}$ & $0.97 \pm 0.13^{\mathrm{b}}$ & $0.99 \pm 0.11^{\mathrm{b}}$ & $0.80 \pm 0.14^{\mathrm{b}}$ \\
\hline$\rho$ Factor & $0.88 \pm 0.13^{\mathrm{a}}$ & $0.94 \pm 0.05^{\mathrm{a}}$ & $0.64 \pm 0.01^{\mathrm{a}}$ & $0.69 \pm 0.06^{a}$ \\
\hline \multicolumn{5}{|c|}{ Aminoacyl-tRNA synthetases } \\
\hline ArgRS & $1.00 \pm 0.06^{\mathrm{a}}$ & $1.04 \pm 0.03^{\mathrm{a}}$ & $0.81 \pm 0.05^{\mathrm{a}}$ & $1.15 \pm 0.06^{\mathrm{a}}$ \\
\hline GlnRS & $1.23 \pm 0.02^{\mathrm{a}}$ & $1.08 \pm 0.14^{\mathrm{a}}$ & $0.97 \pm 0.03^{\mathrm{a}}$ & $1.25 \pm 0.01^{\mathrm{a}}$ \\
\hline GluRS & 1.11 & 0.87 & 0.92 & 1.03 \\
\hline GlyRS & $1.07 \pm 0.03^{\mathrm{a}}$ & 1.06 & $1.26 \pm 0.11^{\mathrm{a}}$ & $1.19 \pm 0.13^{\mathrm{a}}$ \\
\hline IleRS & $1.04 \pm 0.09^{\mathrm{a}}$ & $0.90 \pm 0.05^{\mathrm{a}}$ & $0.88 \pm 0.04^{\mathrm{a}}$ & $0.85 \pm 0.03^{\mathrm{a}}$ \\
\hline LeuRS & $1.12 \pm 0.07^{\mathrm{a}}$ & $0.85 \pm 0.04^{\mathrm{a}}$ & $0.75 \pm 0.08^{\mathrm{a}}$ & $0.86 \pm 0.04^{a}$ \\
\hline LysRS & $1.24 \pm 0.06^{\mathrm{a}}$ & $1.08 \pm 0.01^{\mathrm{a}}$ & 1.09 & $0.97 \pm 0.04^{\mathrm{a}}$ \\
\hline$\beta$-PheRS & $1.08 \pm 0.03^{\mathrm{a}}$ & $0.89 \pm 0.01^{\mathrm{a}}$ & $0.85 \pm 0.06^{\mathrm{a}}$ & $0.50 \pm 0.01^{\mathrm{a}}$ \\
\hline$\alpha$-PheRS & 0.96 & 0.91 & - & 0.76 \\
\hline ValRS & $0.94 \pm 0.07^{\mathrm{a}}$ & 0.93 & $0.73 \pm 0.28^{\mathrm{a}}$ & $1.19 \pm 0.18^{\mathrm{a}}$ \\
\hline
\end{tabular}

The values given here are the differential rates of synthesis of the proteins after 15 min. at $35.5^{\circ}$ relative to the rate at $29.5^{\circ}$. These rates are calculated by dividing the isotope ratio of a protein by the isotope ratio in the total extract, i.e. $\left({ }^{3} \mathrm{H} /{ }^{14} \mathrm{C}\right.$ of spot $) /\left({ }^{3} \mathrm{H} /{ }^{14} \mathrm{C}\right.$ of total extract). Most determinations were made from at least two different electropherograms and the results averaged. Typically, the amount of variation was close to $5 \%$.

"Average \pm one standard deviation, calculated from two electropherograms

- Average \pm one standard deviation, calculated from three electropherograms

" This is the average of determinations of individual ribosomal proteins S3, S4, S5, S7, S12, L1, L2, L3, and L17. The determinations were made as described by, and confirm results obtained by Dennis and Nomura (1974). The genes for several of these proteins are cotranscribed with either the $\alpha$ subunit gene of RNA polymerase or genes for EF-G and EF-Tu (Jaskunas et al., 1975)

d This determination of response of EF-G to the temperature shifts was made by antibody precipitation and electrophoresis on $7.5 \%$ SDS polyacrylamide gels as described by Roberts and Roberts (1975). The labeling protocol was essentially as described in Materials and Methods, but employed a 30 -min. post-pulse chase period

measurements indicate that the aminoacyl-tRNA synthetases do not respond coordinately with one another (Table 1). The responses of ArgRS and ValRS to the restrictions are moderate and are similar to those of EF-Tu and EF-Ts. The remaining synthetases examined show either no response or a mixed response to the restrictions in the stringent and relaxed strains.

\section{Discussion}

Ribosomal Proteins. The synthesis of ribosomal proteins and $r$-protein mRNA has been studied previously in the same bacterial strains under very similar conditions (Dennis and Nomura, 1974, 1975). The results obtained in those studies and in this one are in agreement. It should be noted that, although the 
r-proteins L7 and L12 respond somewhat differently from one another (probably due to the precursor/product relationship that exists between them [Terhorst et al., 1972]), both proteins respond in parallel with each other and with the other $r$-proteins. Protein S1 has not previously been studied in this manner. The co-regulation of S1 and the other $r$-proteins was not a foregone conclusion, since S1 seems to act as an initiation factor (Dahlberg and Dahlberg, 1975) and differs significantly from other $r$-proteins both in molecular weight (Craven et al., 1969; Dzionara et al., 1970; Traut et al., 1969) and in the strength of the physical association with the ribosome (Held et al., 1973; Voynow and Kurland, 1971; Weber, 1972).

Elongation Factors. The elongation factors $E F-G$ and EF-Tu have been studied previously (Furano and Wittel, 1976) under virtually identical conditions, and our results are largely confirmatory. The only significant difference between the experimental protocols of these two studies is in the post-shift temperature ( $35.5^{\circ}$ here, $36.5^{\circ}$ in Furano and Wittel [1976]). This one degree increase in temperature, which inhibits protein synthesis to a greater extent in the val $S^{\text {ts }}$ cultures, increases the strength of the responses of both EF-G and EF-Tu in the val $S^{\text {ts }}$ rel $^{+}$culture (Table 2). In the val ${ }^{\text {ts }}$ relAl (relaxed) culture however, while the strength of the response of EF-G is increased, the strength of the response of EF-Tu is unchanged. This suggests that either EF-Tu synthesis is less sensitive than that of EF-G to restrictions in relA1 cultures, or that the response of EF-Tu is limited to a maximum that has been reached in the $35.5^{\circ}$ temperature shift.

Transcription Proteins. The influence of the relA gene control system on the synthesis of transcription

Table 2. Comparison of Restrictions at $36.5^{\circ}$ and $35.5^{\circ}$

\begin{tabular}{|c|c|c|c|}
\hline Protein & $\begin{array}{l}\text { NF314 } \\
\text { vals }^{+} \text {relA }^{+}\end{array}$ & $\begin{array}{l}\text { NF536 } \\
\text { vals }^{\text {s }} \text { relA }^{+}\end{array}$ & $\begin{array}{l}\text { NF537 } \\
{\text { val } S^{\text {ss }}}_{\text {relA }}\end{array}$ \\
\hline $\begin{array}{r}\text { EF-G } 35.5^{\circ} \\
36.5^{\circ}\end{array}$ & $\begin{array}{l}0.98 \\
1.03\end{array}$ & $\begin{array}{l}0.65 \\
0.34\end{array}$ & $\begin{array}{l}1.47 \\
2.28\end{array}$ \\
\hline $\begin{array}{r}\text { EF-Tu } 35.5^{\circ} \\
36.5^{\circ}\end{array}$ & $\begin{array}{l}1.24 \\
1.15\end{array}$ & $\begin{array}{l}0.92 \\
0.42\end{array}$ & $\begin{array}{l}1.35 \\
1.39\end{array}$ \\
\hline
\end{tabular}

The values given here for the shift to $35.5^{\circ}$ are taken from Table 1 . The values given for the shift to $36.5^{\circ}$ are the averages of three determinations and are taken from Table 1 of Furano and Wittel (1976). The post-pulse chase time employed by Furano and Wittel was $30 \mathrm{~min}$, but increasing the post-pulse chase time in our protocol had no significant effect (see Results). Both this work and that of Furano and Wittel allowed $15 \mathrm{~min}$ between the temperature shift and the isotope pulse. The strains used were identical to those used here proteins was examined to give an idea of how coordinate the responses of a group of functionally related proteins might be. The measurements indicate that the synthesis of the $\alpha$ subunit of RNA polymerase is not like the synthesis of $r$-proteins and may not be subject to stringent control. The gene coding for the $\alpha$ subunit (rpoA) is probably cotranscribed with the genes coding for ribosomal proteins $S 4$ ( $r p s D)$, S11 ( $r p s K)$, and L17 (rplQ) (Jaskunas et al., 1975). The responses of S4, S11, and L17 to the restrictions employed here are typical of the responses of ribosomal proteins (Dennis and Nomura, 1974). These observations seem to indicate that an additional and more complex control regulates the synthesis of the $\alpha$ subunit of RNA polymerase during partial restriction of protein synthesis. The nature of this additional control remains obscure.

The synthesis of the $\beta$ subunit of RNA polymerase (and of $\beta^{\prime}$, assuming that their coordinacy is not altered by the restrictions) appears not to be subject to stringent control. Like $\alpha, \beta$ does not respond to a restriction in the stringent culture. In the relaxed culture during restriction, the differential rate of $\beta$ subunit synthesis seems to drop, while that of $\alpha$, if anything, rises very slightly. The genes for the $\beta$ and $\beta^{\prime}$ subunits of RNA polymerase (rpoB and rpoC, respectively) are very close to ribosomal protein genes ( $r p l A, r p l H, r p l J, r p l K$, and $r p l L$ ) on the E. coli chromosome and (although not seen here) their expression may be related under some other conditions (as may be the case for $\alpha$ and its adjacent $r$-protein genes). In addition some caution must be exercised in interpreting the results with regard to the $\beta$ and $\beta^{\prime}$ subunits since they have been found to turn over rapidly under certain conditions (Kirschbaum et al., 1975; Taketo and Ishihama, 1975; Iwakura et al., 1974).

Aminoacyl-tRNA Synthetases. The aminoacyl-tRNA synthetases do not all respond in parallel to one another to the restrictions employed in this work. ArgRS and ValRS, like EF-Tu and EF-Ts, show moderate stringent responsiveness both in $\mathrm{rel} A^{+}$and relA 1 backgrounds. GlnRS does not show dramatic "stringency" although the regulation of GlnRS is difficult to interpret because of the response to temperature in the unrestricted cultures. The synthesis of LysRS, GluRS, IleRS and LeuRS all show essentially no response to the restrictions, while the $\beta$ (and possibly the $\alpha$ ) subunit of PheRS has a depressed differential rate of synthesis in the restricted relA1 culture. The synthesis of GlyRS seems to respond positively to a restriction, independent of the state of the relA gene. The heterogeneous responses of the aminoacyltRNA synthetases is striking in comparison to the qualitative uniformity with which they respond to 
changes in the steady-state growth rate (Neidhardt et al., 1976) or in a metabolic shift-up (Reeh et al., 1977b).

The response of a particular aminoacyl-tRNA synthetase to these restrictions is difficult to predict. In terms of genetic data, IleRS is the only aminoacyltRNA synthetase whose structural gene (ileS) is known to be very close to a ribosomal gene on the chromosome ( $r p s T$, the structural gene for $r$-protein S20). Yet IleRS (Table 1) does not respond in parallel to the $r$-proteins, or to S20 (Dennis and Nomura, 1974). In terms of metabolic considerations, the aminoacyl-tRNA synthetases specific for biosynthetically related amino acids do not seem to respond together. Although caution in interpretation is needed as the ValRS is mutationally altered, it can be seen that neither ValRS, IleRS, and LeuRS, nor GluRS and GlnRS respond similarly to one another. It appears that the aminoacyl-tRNA synthetases may not be controlled by a single common regulatory element.

There have been suggestions that the aminoacyltRNA synthetases are autogenously regulated (see Neidhardt et al., 1975). One study using anti-phenylalanyl-tRNA synthetase antiserum found that the amount of PheRS cross-reactive material in a PheRS ${ }^{\text {ts }}$ mutant rose rapidly upon shifting the cells to a nonpermissive temperature (Nass, 1968). This observation is consistent with the idea that the native PheRS may act as a repressor. Two of the strains used in this study have a temperature-sensitive ValRS. During the restriction, the synthesis of ValRS does not seem to be unusual in comparison to the other aminoacyl-tRNA synthetases studied. This suggests that either the temperature-sensitivity of the ValRS does not affect its repressor activity or that it is not a repressor of its own synthesis.

Division of the Translation Machinery. Purely through functional considerations, the translation machinery can be divided into two sections: the "core," whose role is to polymerize amino acids into protein, and the "supplier," whose role is to supply the core with aminoacyl-tRNA. At this point it is not certain that core and supplier components are regulated as separate groups, but this possibility is under investigation.

The core components, which include ribosomal RNA, ribosomal proteins, and EF-G, appear to be tightly co-regulated under a variety of conditions including the restrictions reported here. Co-regulation of ribosomal RNA and $r$-proteins is, while not understood mechanistically, what one would expect on the basis of efficiency considerations. It is less clear why EF-G is co-regulated on a $1: 1$ basis with ribosomes, but it may be necessitated by the kinetics of the EF-Gcatalyzed translocation step in protein synthesis. The structural gene for EF-G (fus) appears to be cotranscribed with those for $r$-proteins $\mathrm{S} 7$ (rpsG) and S12 (rpsL) (Jaskunas et al., 1975).

The supplier components, which include transfer RNA, the aminoacyl-tRNA synthetases, and EF-Tu, also appear to be regulated together in steady-state growth, although not coordinately (Neidhardt et al., 1976; Furano, 1975). Even this weak "co-regulation" breaks down when valyl-tRNA is growth ratelimiting. In relA ${ }^{+}$cultures, the restriction leads to a marked reduction in the rates of accumulation of tRNA (Lazzarini and Dahlberg, 1971) and EF-Tu (Furano and Wittel, 1976; this work), but of only some of the aminoacyl-tRNA synthetases. In relA $A^{-}$cultures, restriction leads to increased tRNA accumulation, and an increased differential synthesis rate of EF-Tu (but see Table 2) and of some of the aminoacyl-tRNA synthetases. With respect to the tRNA, it is significant that at least some of it is not properly modified during restrictions of relA $A^{-}$cultures (for example: Kitchingman et al., 1976). The possibility therefore remains that the levels of properly modified tRNAs may be in some way involved in the regulation of the synthesis of EF-Tu and/or the cognate aminoacyl-tRNA synthetases.

Translation proteins that are difficult to categorize as core or supplier proteins are EF-Ts and the initiation factors (IFs). Functionally, EF-Ts is neither a generator nor carrier of aminoacyl-tRNA, but it is required to "recharge" EF-Tu. On the basis of this requirement, one could consider EF-Ts to be a supplier protein, but in terms of predicting its regulation it can be seen that EF-Ts could successfully be regulated with ribosomes on a one-to-one basis (EF-Tu that has been "decharged" through its interaction with a translating ribosome is "recharged" by EF-Ts, so maintaining one EF-Ts per ribosome will satisfy the cell's requirement for EF-Ts regardless of the amount of EF-Tu present). The initiation factors also do not seem to fit into either functional category (although IF2 does carry fmet-tRNA ${ }^{\mathrm{fmet}}$ ). There is no obvious reason to expect the IF's to be co-regulated with one another, but if they are one might expect them to be regulated as core proteins on the basis of our results with $r$-protein S1.

Effects of tufB. Many of the proteins studied here have been examined, under similar conditions, in tufB (see Pedersen et al., 1976) mutants (Reeh et al., 1976a). Although this tufB mutation may be benign, it will be interesting to see if its presence affects the responses of proteins to the restrictions employed.

Acknowledgements. This work was supported by grants, to F.C.N., from the National Science Foundation (BMS 75-01135) and from 
the National Institute of General Medical Sciences (GM 17892); and to P.P.D., from the National Research Council of Canada (NRC A0394). R.M.B. is a predoctoral trainee of the National Institutes of Health (GM 02204). We thank Dr. S. Pedersen for his help in identifying proteins in the electrophoresis system employed.

\section{References}

Blumenthal, R.M., Reeh, S., Pederson, S. : Regulation of transcription factor $\rho$ and the $\alpha$ subunit of RNA polymerase in Escherichia coli B/r. Proc. nat. Acad. Sci. (Wash.) 73, 2285-2288 (1976)

Craven, A.R., Voynow, P., Hardy, S.J.S., Kurland, C.A.: Ribosomal proteins of E. coli. II. Chemical and physical characterization of 30 S proteins. Biochemistry 8, 2906-2915 (1969)

Dahlberg, A.D., Dahlberg, J.E. : Binding of ribosomal protein S1 of Escherichia coli to the $3^{\prime}$ end of $16 \mathrm{~S}$ rRNA. Proc. nat. Acad. Sci. (Wash.) 72, 2940-2944 (1975)

Dennis, P.P.: Regulation of ribosomal and transfer ribonucleic acid synthesis in Escherichia coli B/r. J. biol. Chem. 247, 28422845 (1972)

Dennis, P.P.: In vivo stability, maturation, and relative differential synthesis rates of individual ribosomal proteins in Escherichia coli B/r. J. molec. Biol. 88, 25-41 (1974)

Dennis, P.P., Bremer, H.: Macromolecular composition during steady-state growth of Escherichia coli B/r. J. Bact. 119, 270-281 (1974)

Dennis, P.P., Nomura, M. : Stringent control of ribosomal protein gene expression in Escherichia coli. Proc. nat. Acad. Sci. (Wash.) 71, 3819-3823 (1974)

Dennis, P.P., Nomura, M.: Stringent control of the transcriptional activities of ribosomal protein genes in E. coli. Nature (Lond.) 255, 460-465 (1975)

Dzionara, M., Kaltschmidt, E., Wittmann, H.G.: Ribosomal proteins. XIII. Molecular weights of isolated ribosomalproteins of Escherichia coli. Proc. nat. Acad. Sci. (Wash.) 67, 1909-1913 (1970)

Fiil, N., von Meyenburg, K., Friesen, J.D.: Accumulation and turnover of guanosine tetraphosphate in Escherichia coli. J. molec. Biol. 71, 769-783 (1973)

Furano, A.V.: Content of elongation factor Tu in Escherichia coli. Proc. nat. Acad. Sci. (Wash.) 72, 4780-4784 (1975)

Furano, A.V., Wittel, F.P.: Syntheses of elongation factors Tu and $\mathrm{G}$ are under stringent control in Escherichia coli. J, biol. Chem. 251, 898-901 (1976)

Galibert, F., Lelong, J.C., Larsen, C.J., Boiron, M.: Position of 5-S RNA among cellular ribonucleic acid. Biochim. biophys. Acta (Amst.) 142, 89-94 (1967)

Gordon, J.: Regulation of the in vivo synthesis of the polypeptide chain elongation factors in Escherichia coli. Biochemistry 9, 912-917 (1970)

Held, W.A., Mizushima, S., Nomura, M.: Reconstitution of Escherichia coli $30 \mathrm{~S}$ ribosomal subunits from purified molecular components. J. biol. Chem. 248, 5720-5730 (1973)

Iwakura, Y., Ito, K., Ishihama, A.: Biosynthesis of RNA polymerase in Escherichia coli, I. Control of RNA polymerase content at various growth rates. Molec. gen. Genet. 133, 1-23 (1974)

Jaskunas, S.R., Burgess, R.R., Nomura, M.: Identification of a gene for the $\alpha$-subunit of RNA polymerase at the $s t r-s p c$ region of the Escherichia coli chromosome. Proc. nat. Acad. Sci. (Wash.) 72, 5036-5040 (1975)

Kaltschmidt, E., Wittmann, H.: Ribosomal proteins. VII. Twodimensional polyacrylamide gel electrophoresis for fingerprinting of ribosomal proteins. Anal. Biochem. 36, $401-412$ (1970)

Kirschbaum, J.B., Claeys, I.V., Nasi, S., Molholt, S., Miller, J.: Temperature-sensitive RNA polymerase mutants with altered subunit synthesis and degradation. Proc. nat. Acad. Sci. USA 72, 2375-2379 (1975)

Kitchingman, G.R., Webb, E., Fournier, M.J.: Unique phenylalanine transfer ribonucleic acids in relaxed control Escherichia coli: genetic origin and some functional properties. Biochemistry 15, 1848-1857 (1976)

Lazzarini, R.A., Dahlberg, A.E.: The control of ribonucleic acid synthesis during amino acid deprivation in Escherichia coli. J. biol. Chem. 246, 420-429 (1971)

Nass, G.: In Molecular genetics (H.G. Wittmann; H. Schuster, ed.), pp. 147-154. Berlin-Heidelberg-New York: Springer 1968

Neidhardt, F.C., Bloch, P., Pedersen, S., Reeh, S.: Chemical measurement of steady-state levels of ten aminoacyl transfer ribonucleic acid synthetases in Escherichia coli. J. Bact., in press (1976)

Neidhardt, F.C., Parker, J., McKeever, W.G.: Function and regulation of aminoacyl-tRNA synthetases in prokaryotic and eukaryotic cells. Ann. Rev. Microbiol. 29, 215-250 (1975)

Nikolaev, N., Silengo, L., Schlessinger, D.: Synthesis of a large precursor to ribosomal RNA in a mutant of Escherichia coli. Proc. nat. Acad. Sci. (Wash.) 70, 3361-3365 (1973a)

Nikolaev, N., Silengo, L., Schlessinger, D.: A role for RNase III in processing of $\mathrm{RRNA}$ and mRNA precursors in Escherichia coli. J. biol. Chem. 248, $7967-7969$ (1973b)

O'Farrell, P.H.: High resolution two-dimensional electrophoresis of proteins. J. biol. Chem. 250, 4007-4021 (1975)

Pedersen, S., Blumenthal, R.M., Reeh, S., Parker, J., Lemaux, P., Laursen, R.A., Nagarkatti, S., Friesen, J.D.: A mutant of Escherichia coli with an altered elongation factor Tu. Proc. nat. Acad. Sci. (Wash.) 73, 1698-1701 (1976)

Reeh, S., Pedersen, S., Friesen, J.D.: Biosynthetic regulation of individual proteins in relA $A^{+}$and relA strains of Escherichia coli during amino acid starvation. Molec. gen. Genet. 149, 279-289 (1976a)

Reeh, S., Pedersen, S., Neidhardt, F.C.: Transient rates of synthesis of five aminoacyl transfer ribonucleic acid synthetases during a shift-up of Escherichia coli. J. Bact., in press (1977)

Roberts, J.W., Roberts, C.W.: Proteolytic cleavage of bacteriophage lambda repressor in induction. Proc. nat. Acad. Sci. (Wash.) 72, 147--151 (1975)

Skjold, A., Juarez, H., Hedgcoth, C. : Relationships between deoxyribonucleic acid, ribonucleic acid and specific transfer ribonucleic acids in Escherichia coli $15 \mathrm{~T}^{-}$at various growth rates. J. Bact. 115, 177-187 (1973)

Stent, G., Brenner, S. A genetic locus for the regulation of ribonucleic acid synthesis. Proc. nat. Acad. Sci. (Wash.) 47, 2005-2014 (1961)

Taketo, M., Ishihama, A.: In: Control of Ribosome Synthesis (Kjeldgaard, N.O., Maaløe, O., Thaysen, J.H., eds.). Copenhagen: Munksgaard 1975

Terhorst, C., Möller, W., Laursen, R., Wittmann-Liebold, B.: Amino acid sequence of a $50 \mathrm{~S}$ ribosomal protein involved in both EF-G and EF-T dependent GTP-hydrolysis. FEBS. Letters 28 , 326-328 (1972)

Traut, R.A., Delius, H., Ahmad-Zadeh, C., Bickle, T.A., Pearson, P., Tissières, A.: Ribosomal protein of E. coli: Stoichiometry and implication for ribosome structure. Cold. Spr. Harbor Symp. quant. Biol. 34, 25-38 (1969)

Voynow, P., Kurland, C.A.: Stoichiometry of the 30 S ribosomal proteins of E. coli. Biochemistry 10, 517-524 (1971)

Weber, H.J.: Stoichiometric measurements of $30 \mathrm{~S}$ and $50 \mathrm{~S}$ ribosomal proteins from Escherichia coli. Molec. gen. Genet. 119 , 233-248 (1972)

\section{Communicated by H.G. Wittmann}

Received July 14 / August 16, 1976 